\title{
A TECNOLOGIA E O ENSINO: O USO DE FERRAMENTAS TECNOLÓGICAS COMO APOIO NO APRENDIZADO DA LÍNGUA INGLESA*
}

\section{TECHNOLOGY AND TEACHING: THE USE OF COMPUTING TECHNOLOGY AS A TOOL SU- PPORT IN ENGLISH LEARNING}

\begin{abstract}
Resumo
Este artigo teve o objetivo de analisar e sugerir formas de permitir que os alunos tenham acesso a softwares que venham de encontro com o que estão aprendendo em sala. Desta forma, se torna importante que escolas de idiomas possuam plataformas interativas para que o aluno tenha acesso e possa praticar conteúdo visto em sala de aula. No entanto, as plataformas de maneira alguma substituem conteúdos apresentados na sala pelo professor, mas servem como meio de reforço, permitindo que o aluno continue praticando. A aprendizagem de um novo idioma demanda disciplina e continuidade, sendo fundamental que o aprendiz de uma nova língua permita que o novo idioma faça parte do seu dia a dia. Neste contexto, percebe-se a importância de escolas de idiomas investirem em ferramentas tecnológicas na busca de engajar e encantar seus alunos. A partir de uma revisão bibliográfica e uma pesquisa de campo aplicada em uma escola de idiomas localizada no Planalto Norte de Santa Catarina, foi possível traçar estratégias e táticas para a aplicabilidade do tema em sala de aula. Essas plataformas não podem ser vistas apenas de forma mercadológica, é necessário que sejam embasadas de forma pedagógica, uma vez que as atividades apresentadas nas plataformas devem ser extensão da sala de aula, buscando trazer o mesmo método de ensino que a escola promove. As plataformas educativas podem variar de acordo com a necessidade e disponibilidade de cada escola, contudo, este projeto trouxe algumas sugestões como, jogos, quiz (perguntas e respostas), aplicativos e realidade aumentada.
\end{abstract}

Palavras-chave: Inglês; Ferramentas tecnológicas; Plataformas educativas.

\begin{abstract}
This article aimed to analyze and suggest ways to allow students to have access to software in a way that allows students to have access to software that complements what they have learned in classroom. So, it is important that Language Schools have its own interactive platforms where its students could access and practice the subjects seen in the classroom. However, those platforms in no way should replace the subjects shown by the teacher, but provide a way as a reinforcement, allowing the students to keep on practicing the language. Learning a new language demands discipline and continuity, which is fundamental to a new language learner allows the new language make part in a day-to-day. In this context, we can notice the importance of language schools to invest in technological tools, seeking to engage and delight its
\end{abstract}

\footnotetext{
* Artigo Original: Recebido em 05/06/2020 - Aprovado em 06/11/2020.

${ }^{1}$ Especialista em Tecnologias da Informática na Educação/ Universidade Estadual de Londrina (UEL), Graduado em Administração de Empresas/ Universidade do Contestado (UNC). Tutor no Centro Universitário Leonardo da Vinci (UNIASSELVI). Canoinhas/SC, Brasil. e-mail: 1.leandro.oliveira@outlook.com ORCID: https://orcid.org/0000-0002-1038-2976
} 
students. From a bibliographic review and field research applied in a language school located in the Planalto Norte of Santa Catarina, it was possible to outline strategies and tactics for the applicability of the theme in the classroom. Those platforms cannot be seen only as marketing, it is necessary they should be based on pedagogical skills, once the activities shown in those platforms should be an extension of the classroom, seeking to bring the same method provided by the school. Educational platforms may vary according to the need and availability of each school, however, this project has brought some suggestions such as games, quiz, applications and augmented reality.

Key-Words: English; Technological tools; Educational platforms.

\section{Introdução}

O inglês e a informática são áreas de bastante visibilidade mercadológica onde o domínio e habilidade com essas áreas colaboram para que o profissional tenha destaque no mercado de trabalho. A educação, agregada com o uso da informática pode colaborar para que ocorra esse desenvolvimento nas salas de aula ou na sua extensão. Sendo a informática e tecnologias em geral algo que as crianças, adolescentes e adultos se sentem confortáveis e familiarizadas com o seu uso, este projeto propõe verificar mídias digitais utilizadas como ferramentas de apoio aos conteúdos da língua inglesa vistos em sala de aula.

Entretanto, estas mídias de maneira alguma substituem o conteúdo visto em sala, apenas são disponibilizadas para que os alunos mantenham contato com a língua e reforcem as estruturas e vocabulário aprendidos.

Desta forma, como objetivo principal, pretende-se responder a seguinte questão: Como as ferramentas tecnológicas podem ser utilizadas em escolas de idiomas para fornecer suporte ao aprendizado da língua inglesa?

Como objetivo específico buscar-se-á analisar as ferramentas de uma escola de idiomas do planalto norte de Santa Catarina de maneira isolada, verificando os benefícios que podem trazer para o aprendizado do aluno.

Justifica-se a realização deste estudo pelo cenário tecnológico em que os alunos estão envolvidos, independentemente da idade ou nível de proficiência do idioma e pelo fato de conseguir engajar os alunos no processo de aprendizagem da nova língua.

O domínio de uma segunda língua tem sido cada vez mais exigido nas mais diversas áreas no mercado de trabalho. Preparar e capacitar os alunos para esta realidade é papel fundamental das escolas, instituições e profissionais da educação.

Uma vez que o inglês é uma das línguas mais faladas no mundo, quanto mais a língua se torna conhecida mais os países fazem uso e tornam a língua importante e utilizada de uma maneira única, aumentando desta forma o seu status de importância dentro de uma sociedade. Quando isso ocorre em larga escala, como é o caso inglês, onde em um cenário global a língua é considerara essencial para diversos países em todo o mundo, fazendo do inglês uma língua necessária e fundamental dentro da sociedade em diversos setores.

And access to knowledge is the business of education. When we investigate why so many nations have in recent years made English an official language or chosen it as their chief foreign language in schools, one of the most important reasons is always educational - in the broadest sense. (CRYSTAL, 2003, p.110).

E o acesso ao conhecimento é o negócio da educação. Quando investigamos por que tantas nações nos últimos anos fizeram do inglês uma língua oficial orquestrando-o como sua principal língua estrangeira nas escolas, uma das razões mais importantes é sempre educacional - no sentido mais amplo (CRYSTAL, 2003, p.110, tradução do autor).

Esta importância dada a língua permite que cada vez mais usuários a estudem, entendam, falem e tornem a língua algo vivo dentro deles, a informática vem de encontro e acompanha toda esta evolução. 
A informática vem crescendo e a interatividade, conectividade e familiaridade dos alunos com aparelhos tecnológicos são notórias, desta maneira justifica-se a importância deste tema na atualidade e a utilização da informática para o ensino da língua inglesa.

Este projeto está estruturado nos seguintes tópicos: Definição da Informática na Educação, o qual abordará uma visão geral do assunto principal relacionado à proposta do projeto; Uso das tecnologias de informação e comunicação (TIC) no Ambiente Escolar proporcionará o conhecimento das ferramentas que o professor pode utilizar a fim de incrementar e aprimorar suas aulas; O uso da informática no ensino da língua inglesa trará técnicas e modelos de ensino da língua inglesa em sala de aula com o auxílio das TIC, bem como análise dos processos utilizados.

\section{Fundamentação teórica}

\subsection{Informática na educação}

A presença da informática, internet e tecnologias são comuns na vida de muitas pessoas, o que muitas vezes se torna algo indispensável com o atual ritmo de trabalho e de necessidade de comunicação rápida e instantânea.

Desta forma, se faz presente também no âmbito educacional, ganhando cada vez mais espaço em atividades com alunos, podendo ser incluída e trabalhada em qualquer disciplina.

A educação necessita estar atenta às novidades e não se marginalizar, tornando-se obsoleta e sem flexibilidade. Algumas dessas mudanças podem ser realizadas pelo professor que, tendo uma visão de futuro e mente aberta para refletir criticamente sobre sua prática no processo de ensino-aprendizagem, torna-se um agente ativo no sistema educacional. (TAJRA, 2019, p. 07).

Com as crianças e adolescentes este cenário não é diferente, muitas vezes com habilidades e facilidades de familiarização maiores com a tecnologia do que muitos adultos, esses usuários se sentem encantados e animados quando o assunto é tecnologia.
"Nesta lógica, destaca-se a participação e formação autônoma do aluno, ao mesmo tempo em que se defende o desenvolvimento de uma pedagogia mais crítica". (PEIXOTO; ARAÚJO, 2012, p. 2).

Neste cenário, podemos destacar a importância da atualização constante do professor e suporte das direções para que o educador tenha liberdade e consiga obter qualidade no ensino utilizando as TIC em sala de aula.

\subsection{Uso das TIC no ambiente escolar}

Fazer uso das TIC vem sendo encontrada mais comumente nas salas de aula devido à facilidade e a rapidez nas informações. Atualmente, as escolas estão alterando a sua estrutura e forma de trabalho de maneira a se adequar com as tecnologias, fazendo uso e aproveitando ao máximo esses recursos. Trazendo para escola, melhores computadores, máquinas de xérox, internet, ou seja, permitindo que o trabalho administrativo escolar seja desempenhado acompanhando as tecnologias atuais.

Assim, fazem-se necessárias novas metodologias que levam em consideração essa nova possibilidade de ensino. E, para que os professores adotem novas metodologias eles precisam conhecer as tecnologias, usálas, identificar suas vantagens e limites - o que pode ocorrer por meio de cursos, pela auto-formação e por vivências/ experiências. (FELDKERCER; MATHIAS, 2011, p. 86).

Essa tecnologia ganha espaço dentro da sala de aula, uma vez que este tema está sendo abordado e utilizado pelos profissionais da educação com mais frequência.

Desse modo, é argumentado que a presença de um educador em ambientes de aprendizagem baseados em TIC é fundamental. Sem a mediação de um educador ou de um agente de aprendizagem, a interação do aprendiz com pessoas e objetos é limitada, não atingindo seu potencial como meio de construção de conhecimento. (CAPOZZOLI, 2019, p. 133). 
Neste contexto, percebe-se a importância de entender que o professor interminavelmente desempenhará papel fundamental no desenvolvimento da aula e na orientação e ensino da disciplina para os alunos. As tecnologias devem ser utilizadas como meio de auxiliar o professor a criar um ambiente descontraído e diferenciado para que possa aguçar o interesse do aluno a fim de proporcionar maior desempenho dos mesmos diante ao conteúdo apresentado.

As metodologias precisam acompanhar os objetivos pretendidos. Se queremos que os alunos sejam proativos, precisamos adotar metodologias nas quais eles se envolvam em atividades cada vez mais complexas, em que tenham de tomar decisões e avaliar resultados, com apoio de material relevantes. Se queremos que sejam criativos, eles precisam experimentar inúmeras novas possibilidades de mostrar sua iniciativa. Desafios e atividades podem ser dosados, planejados, acompanhados e avaliados com apoio de tecnologias. (BACICH; NETO; TREVISANI, 2015, p. 06-07).

O apoio das direções e demais envolvidos no processo de aprendizagem é fundamental para auxiliar o professor no desenvolvimento de suas aulas utilizando as TIC, bem como proporcionar um ambiente onde todos estejam realmente em sintonia e em sincronia para que o uso das TIC seja de fato uma estratégia para alterar o cenário atual das salas de aula, a fim de permitir que o aluno obtenha maior experiência e contato com as disciplinas as quais está sendo exposto.

\subsection{O uso da informática no ensino da língua inglesa}

Diante das grandes mudanças em nossa sociedade, gerenciada, em larga escala pelos recursos tecnológicos, o uso das Tecnologias de Informática se alia à escola como meio pedagógico para enriquecer o ambiente educacional.

O princípio do conhecimento está ligado à transitoriedade, às grandes e velozes mudanças da contemporaneidade; a escola não cria objetos de conhecimento próprios dela, mas transpõe, para sala de aula, objetos de circulação social, construídos histórica e socialmente. As tecnologias digitais são um desafio para a construção de conhecimento na escola, não somente pelo conhecimento e apropriação das próprias ferramentas, mas também pelo impacto no registro, pesquisa e nos diversos procedimentos de estudo. Sua presença é fundamental, pois viabiliza práticas sociais atuais, que precisam ser tematizadas e experimentadas na escola. (BACICH; MORAN, 2018, p.109).

Diante deste cenário, as escolas estão buscando o desenvolvimento e o alinhamento das disciplinas trabalhadas em associação com a informática e a tecnologia.

No que diz respeito às tecnologias para ensino da língua inglesa, atualmente existem algumas ferramentas com o objetivo de proporcionar uma experiência mais realista para o aluno, intercalando com os conteúdos vistos em sala de aula, através de portais com jogos, quiz (perguntas e respostas) e aplicativos no qual o aluno pode praticar atividades de escrita, áudio e fala.

Desta forma o aluno tem a possibilidade de praticar o idioma com qualidade, estudando e treinando as habilidades de escuta, escrita, leitura e fala. Além de ser uma maneira de o aluno rever os conteúdos de forma lúdica e divertida, o aluno também faz uso de ferramentas de informática, como programas e visualizações de gráficos quando utiliza plataformas como estas. Uma vez que os alunos sejam eles crianças, jovens ou adultos estão bastante familiarizados com ferramentas tecnológicas.

Este método possui também caráter mercadológico o que pode ser interessante para o financeiro da escola, contudo, o foco deste tópico e deste projeto é avaliar a proposta pedagógica que estas plataformas proporcionam.

Os softwares devem servir como uma plataforma para rever e reforçar conteúdos vistos nas aulas. Possuir um layout prático e interativo para despertar interesse e curiosidade dos alunos. As atividades precisam ocorrer de forma que o aluno interaja e reveja os conteúdos que já aprendeu em sala de aula, contendo exercícios e jogos como forma de exercitar o conteúdo aprendido. Existe uma grande 
variedade de aplicativos gratuitos e pagos na internet com o objetivo de ensinar inglês. Cada um com sua particularidade e didática já definidas.

\subsection{Tecnologias em sala de aula em escolas de idiomas}

Atualmente muitas escolas de idiomas estão investindo de maneira considerável em tecnologias, não somente como função de praticar o idioma fora da sala de aula, mas as incluindo dentro da sala de aula, como apoio ao professor e ao aluno.

As escolas de idiomas vêm sendo equipadas com tabletes, televisores, e aplicativos próprios para execução de áudio, vídeo e slides com apresentação do tema da aula, até mesmo quadros interativos estão sendo utilizados, sempre alinhados com a área pedagógica da escola, uma vez que todos esses recursos são utilizados para o aprendizado do aluno e desenvolvimento do idioma. Faz-se necessário então um olhar pedagógico em cada atividade e em cada ferramenta utilizada.

Tal como citado por Camargo e Daros (2018, p. 04) "A inovação é uma das formas de transformar a educação". A inclusão de tecnologias em sala de aula faz parte desta inovação e contribui para que alunos e sociedade em geral percebam a mudança nas escolas com professores qualificados e treinados para manuseio dessas ferramentas.

Do ponto de vista mercadológico, ferramentas desta natureza podem agregar visibilidade para a escola. Por outro lado, do ponto de vista pedagógico, o qual é o objetivo da análise deste tópico e deste projeto, além de unir a informática e demais ferramentas tecnológicas no ensino da língua inglesa para contribuir no progresso e processo de aprendizagem do aluno, a tecnologia promove um ambiente inovador, permitindo que o aluno mantenha contato com o idioma por mais tempo.

Os profissionais que utilizam essas ferramentas em sala devem receber treinamento, mas não necessariamente precisam dominar a informática ou tecnologias, porém, devem estar abertos e dispostos a aprender e moldar as suas aulas para trabalhar em conjunto com essas ferramentas de apoio, uma vez que tecnologia faz parte do nosso dia a dia.

As pessoas estão cada vez mais conectadas. A cultura, as instituições e trajetória da sociedade caminham para um universo cada vez mais inter-relacionado. Por exemplo, estabelecem-se redes de comunicação por meio de mídias participativas, nas quais se apresentam notícias, fatos e novos meios de entretenimento em tempo real no mundo todo. Pessoas, agentes públicos e privados aparecem conectados. (CAMARGO; DAROS, 2018, p. 13).

Algumas escolas estão investindo em videoconferências através do Google for Education, uma plataforma do Google voltada exclusivamente para educação. Neste modelo, é possível realizar aulas de conversação com pessoas de outros países, por exemplo. Uma aula de imersão sem sair do país de origem.

Em todos os casos, o professor continua sendo papel fundamental para o desenvolvimento e direção da aula, uma vez que atua também como tutor em sala, promovendo interação entre os alunos com as tecnologias disponíveis para uso e pratica do idioma, garantindo que o aluno tire máximo proveito das ferramentas e que consiga aplicar o que vem aprendendo de forma satisfatória.

\section{Material e métodos}

\subsection{Pesquisa bibliográfica}

Para Cervo e Bervian (1996) a pesquisa bibliográfica procura explicar um problema a partir de referências teóricas publicadas em documentos. Pode ser realizada independentemente ou como parte da pesquisa descritiva ou experimental. Em ambos os casos, busca conhecer e analisar as contribuições culturais ou cientificas do passado existente sobre um determinado assunto, tema ou problema.

Nesse contexto o autor enfatiza que a pesquisa bibliográfica constitui parte da pesquisa descritiva ou experimental, quando é feita com o intuito de recolher informações e conhecimentos prévios acerca de um problema para o qual se procura resposta ou acerca de uma hipótese que se quer experimentar.

Para este projeto, a pesquisa bibliográfica ocorreu em livros e artigos acadêmicos relacionados ao tema de forma a contribuir para a resolução do problema o qual originou este projeto de pesquisa. 
Através da pesquisa bibliográfica foi possível desenvolver estratégias e sugestões para que o objetivo do trabalho fosse alcançado.

Utilizando textos e artigos que tratavam do assunto em questão, unindo temas e os associando com o objetivo geral do trabalho a fim de gerar os resultados para desenvolver meios de criar e incentivar a utilização de ferramentas tecnológicas como apoio ao aprendizado da língua inglesa.

\subsection{Pesquisa de campo}

Tal como citado por Gil (2002) o estudo de campo focaliza uma comunidade, que não é necessariamente geográfica, já que pode ser uma comunidade de trabalho, de estudo, de lazer ou voltada para qualquer outra atividade humana. Basicamente, a pesquisa é desenvolvida por meio da observação direta das atividades do grupo estudado e de entrevistas com informantes para captar suas explicações e interpretações do que ocorre no grupo. Esses procedimentos são geralmente conjugados com muitos outros, tais como a analise de documentos, filmagem e fotografias.

No estudo de campo, o pesquisador realiza a maior parte do trabalho pessoalmente, pois é enfatizada importância de o pesquisador ter tido ele mesmo uma experiência direta com a situação de estudo.

A pesquisa de campo deste projeto se deu através de análise de programas, ferramentas e aplicativos já existentes em uma escola de idiomas localizada no Planalto Norte de Santa Catarina.

\section{Resultado e discussão}

\subsection{Plataformas educativas}

As escolas de idiomas necessitam iniciar de forma acelerada a inclusão de cada vez mais plataformas virtuais para uso dos alunos como forma de engajamento e prática do idioma, desde jogos até utilização de realidade aumentada. Contudo, grandes estudos por traz destes lançamentos precisam acontecer de forma bastante planejada e cautelosa, uma vez que o intuito não deve ser apenas no que diz respeito à área mercadológica. Deve haver uma preocupação para que o pedagógico seja incluído em cada programa.
Algumas escolas têm como premissa que as plataformas interativas devam seguir as metodologias de ensino da rede, trazendo similaridade de conteúdo aplicado pelo professor durante as aulas. Estas estratégias funcionam de forma bastante efetiva uma vez que exige da escola um trabalho pedagógico grande para que as atividades online sigam os padrões de ensino da própria rede.

Se a escola optar por utilizar um aplicativo ou programa já existente é necessário moldar e adaptar as atividades para que não seja simplesmente passatempos para os alunos e sim uma ferramenta que agregue conhecimento, prática e envolvimento com o idioma.

Existem programas e aplicativos gratuitos na internet em formato de softwares livres os quais permitem o download e atualização sem violação de direitos autorais. O que pode servir como uma estratégia para escola que ainda não decidiu quais ferramentas utilizará, podendo utilizar ferramentas já existentes para moldar e desenvolver suas próprias ferramentas de acordo com as necessidades de seus alunos.

Abaixo alguns aplicativos que podem ser utilizados em uma escola de idiomas:

- Bussu

$\mathrm{O}$ aluno pode escolher o inglês ou qualquer outro idioma e acessar as fichas de vocabulário, que permitem o aprendizado de muitas palavras.

- Duolingo

Toda a aprendizagem é estruturada como se fosse um jogo. À medida que o aluno evolui os conteúdos vão ficando mais difíceis.

- Menrise

Neste aplicativo há exercícios de revisão, dicas de vocabulário e até mesmo uma rede social colaborativa, na qual é possível adicionar um grupo e organizar cursos online coletivos.

- My English Online

Este site é um serviço que foi criado pelo Ministério da Educação através do programa Idioma Sem Fronteiras (IsF). Nele, é possível encontrar e-books gratuitos para downloads, arquivos de vídeo e áudio e testes para que o 
usuário possa acompanhar como está sendo o seu desempenho.

Desta forma, é possível que as escolas desenvolvam ou utilizem programas já existentes onde o professor possa criar chats ou fóruns com os alunos, em grupo ou individual, preparar exercícios ou atividades de áudio. No caso de alunos menores de idade é necessário que seja possível incluir um responsável para acompanhar, ou seja, os pais e/ou a direção da escola podem verificar o que está sendo trabalhado no aplicativo ou site. Desta forma, a escola pode garantir um acompanhamento pedagógico eficiente para cada aluno.

O professor pode agendar tarefas fora do horário de aula dos alunos, manhã, tarde ou noite para reforçar o que foi visto em sala de aula, como por exemplo, exercícios extras, de forma que os alunos pratiquem e participem de forma ativa de todas as atividades.

Os alunos podem ser direcionados para o laboratório de informática a fim de realizar exercícios e atividades extras para reforçar o conteúdo. Pode ainda haver a vinculação de todos os alunos através de um cadastro de cada estudante para acessar a plataforma, desta maneira é possível unir todos para participarem de jogos, como forma de competição, estimulando o aprendizado, com momentos de descontração e diversão. Permitindo que os alunos aprendam por experiência, ou seja, vivenciando a situação para utilizar o idioma de forma realista e efetiva.

As plataformas poderão inclusive, permitir que ao professor incluir atividades relacionadas exatamente com a matéria que os alunos acabaram de participar em sala. Com didática e conteúdo sendo trabalhados de forma flexível, possibilita que o professor tenha liberdade para trabalhar os conteúdos dentro da plataforma.

\subsection{Análise das plataformas educativas utilizadas em uma escola de idiomas}

Este projeto de pesquisa analisou de forma minuciosa através de uma pesquisa de campo as plataformas educativas utilizadas por uma escola de idiomas do planalto norte de Santa Catarina que por sua vez possui uma metodologia bastante específica e que procura trazer o mesmo método para as ferramentas tecnológicas disponibilizadas para seus alunos. Através da pesquisa de campo foi possível analisar cada plataforma utilizada pela escola que permitiu este estudo. Com olhar voltado ao pedagógico a análise trouxe resultados satisfatórios.

A primeira ferramenta analisada trata-se de jogos para os alunos se divertirem enquanto aprendem e reveem os conteúdos que tiveram em sala de aula. Os jogos são os mais variados, podendo ser jogos de aventuras onde o aluno irá enfrentar desafios e conforme forem seus acertos poderá ir avançando os níveis no jogo, podendo inclusive ser jogado em grupo ou individual, competindo com demais alunos da escola, contudo, cada aluno joga conforme o seu nível atual do idioma. Jogos de memória e caça-palavras também fazem parte da lista de jogos que a escola oferece, os quais permitem a revisão de palavras atreladas com imagens para facilitar o aprendizado.

O segundo modelo utilizado pela escola é o de formato de quiz, ou seja, perguntas e respostas, permitindo que o aluno pratique e relembre frases e expressões que aprendeu nas aulas anteriores.

Na sequência, a pesquisa de campo proporcionou o estudo acerca da utilização de um aplicativo para dispositivos móveis onde o aluno pode praticar todas as habilidades da língua inglesa no que diz respeito à fala, escrita e leitura do idioma. O aplicativo se encarregará de fazer as correções, caso forem necessárias. Este modelo de plataforma é interessante, pois permite que o aluno perceba onde está sua dificuldade e consiga trabalhar para melhorá-la.

Abaixo a descrição individual dos programas oferecidos aos alunos pela escola onde a pesquisa de campo foi aplicada:

- Jogos - Os alunos podem rever os conteúdos de forma divertida, individual ou em grupo, uma vez que existe opção de executar jogos online. O aluno poderá competir com outros alunos de todos os níveis, porém os exercícios durante o jogo aparecerão de acordo com o nível real de cada aluno.

Em jogos desta natureza, é possível que o aluno acompanhe a sua pontuação e desempenho durante todo o jogo.

Permitir que os jogos ocorram online em grupo ou individual, possibilita que o aluno possa iniciar e continuar de onde parou ou onde desejar.

Os jogos normalmente são de aventura onde o aluno, por exemplo, irá precisar enfrentar 
desafios para passar de nível, também é possível encontrar jogos de memória ou quebra-cabeças.

- Quiz - Jogos de perguntas e respostas para que o aluno pratique o vocabulário aprendido em sala, podendo alternar entre o nível atual que está cursando bem como voltar níveis anteriores para revisar vocabulário mais antigo, uma forma de manter-se atualizado e relembrar o que já aprendeu.

Caracteriza-se como um jogo de estratégia pedagógica, onde o aluno verá estruturas, expressões e palavras que viu em sala de aula. Neste momento, a escola reforça o entendimento do aluno quanto ao método em que a escola aplica, pois os jogos de perguntas e respostas trazem estruturas de gramáticas vinculadas com a forma que foi explicada em sala pelo professor. Desta forma, unindo o que o aluno já ouviu pelo professor com o que está apresentado no jogo. Permitindo engajamento do aluno com relação ao método que a escola utiliza.

- Aplicativos - $\mathrm{O}$ aluno tem a possibilidade de ouvir áudios e praticar pronúncia através do aplicativo. O aplicativo permite que o aluno ouça e então repita o que ouvir, o aplicativo se encarregará de entender o que o aluno falou e fará as correções necessárias, caso houver. É um exercício bem interessante, uma vez que permite que o aluno perceba onde está a sua dificuldade, e possa trabalhar nela.

Como o aplicativo é instalado em dispositivos móveis, os alunos podem praticar em qualquer lugar que desejarem, seja no intervalo, no caminho para escola ou trabalho ou até mesmo antes do início da aula.

- $\quad$ Realidade aumentada - Não se caracteriza como pedagógico, porém pode ser uma ponte para despertar o interesse dos mais jovens para com o curso e consequentemente com a aprendizagem do idioma. Uma vez que o objetivo de todas as plataformas é de conseguir engajamento do aluno com o aprendizado.

A realidade aumentada pode ser utilizada nos livros dos alunos, por exemplo, ou em alguns exercícios específicos onde através de um aplicativo o aluno pode ver os movimentos de personagens ou até mesmo ouvir o texto ou uma apresentação de uma nova unidade.

Importante salientar que todas essas atividades devem ter acompanhamento pedagógico, pois se o aluno não consegue passar de fase no jogo ou se o aplicativo sempre o corrige, por exemplo, é interessante haver intervenção pedagógica, seja do coordenador ou do próprio professor.

Auxiliar o aluno nessa trajetória de aprendizagem é importante, ele não irá se sentir sozinho nessa caminhada e saberá que pode contar com a escola e com os profissionais que atuam nela.

Para isso, cada aplicativo ou programa deve gerar relatórios onde a escola possa ter acesso, para então realizar um acompanhamento pedagógico eficiente para cada situação e para cada aluno.

\section{Considerações finais}

Este artigo teve como objetivo apresentar de forma clara à importância e a necessidade de trabalhar a informática no ensino da língua inglesa em escolas de idiomas.

Através de pesquisa bibliográfica e sugestões de alguns softwares que podem ser disponibilizados aos alunos como ferramenta de auxílio e reforço dos conteúdos vistos em sala de aula, onde os alunos podem aprender se divertindo, revendo conteúdos, aprendendo novas expressões ou palavras em inglês. Pretendendo proporcionar motivação, interesse e engajamento dos alunos quanto à aprendizagem de uma nova língua.

Permitindo desta forma, que o ensino da língua esteja atrelado às tecnologias e que seja constante na vida dos estudantes, o que é fundamental para que o aprendizado ocorra de forma eficaz.

Assim sendo, este projeto trouxe algumas opções de jogos e atividades extras envolvendo tecnologias de informática para o ensino da língua inglesa. A escola que não possui material tecnológico próprio pode fazer uso de aplicativos ou softwares livres para utilização em sala de aula ou laboratórios de informática onde o professor pode conduzir atividades que estejam atreladas tanto com o inglês quanto com a informática. Além de permitir que o 
aluno utilize ferramentas a qual está familiarizado e também consiga praticar o novo idioma que está aprendendo.

A pesquisa de campo proporcionou análise de plataformas virtuais educativas utilizadas por uma escola de idiomas localizada no Planalto Norte de Santa Catarina. Com o objetivo de estudo de cada modelo disponibilizado pela escola é possível ter um norte para aplicabilidade em outras escolas ou instituições, com ferramentas flexíveis e que se adaptem a realidade de cada escola.

Todas essas atividades e sugestões caracterizam-se como ferramentas de apoio para o aprendizado não podendo ser substituto da aula propriamente dita.

Estas ferramentas, por fazerem parte do dia a dia dos alunos, independente de sua idade, podem servir como um facilitador para que o aluno busque cada vez mais conhecimento.

Aprender uma nova língua é algo que deve ser constante e o fator motivacional é importante nesse processo. Utilizar as ferramentas de informática nesse processo de aprendizagem permite que o aluno utilize algo que já está acostumado em prol de uma atividade que ainda está aprendendo ou que esta procurando praticar.

Permitindo que a escola, coordenadores e professores consigam acompanhar de perto o desempenho de seus alunos.

\section{Referências}

BACICH, Lilian; MORAN, José. Metodologias ativas para uma educação inovadora: um abordagem teórico-prática. Porto Alegre: Penso, 2018 .

BACICH, Lilian; NETO, Adolfo Tanzi; TREVISANI, Fernando de Mello. Ensino Híbrido: personalização e tecnologia na educação. Porto Alegre: Penso, 2015.

CAMARGO, Fausto; DAROS, Thuinie. A sala de aula inovadora: estratégias pedagógicas para fomentar o aprendizado ativo. Porto Alegre: Penso, 2018.

CAPOZZOLI, Camila Brito Cavalcanti. Relato de experiência do uso das TIC no ensino de escrita em aulas de inglês. Revista X, Curitiba, n. 6, p.128142, 2019.
CERVO, Amado Luiz, BERVIAN, Pedro Alcino. Metodologia Científica. 4.ed. São Paulo: Makron Books, 1996.

CRYSTAL, David. English as a global language. 2ed. Cambridge University Press. 2003.

FELDKERCHER, Nadiane; MATHIAS, Carmem Vieira. Uso das TIC na Educação Superior presencial e a distância: a visão dos professores. Pelotas. 2011.

GIL, Antônio Carlos. Como elaborar projeto de pesquisa. 4.ed. São Paulo: Atlas, 2002.

MARCONI, Marina de Andrade, LAKATOS, Eva Maria. Metodologia do trabalho científico: procedimentos básicos, pesquisa bibliográfica, projeto e relatório, publicações e trabalhos científicos. 6.ed. São Paulo: Atlas, 2001.

PEIXOTO, Joana; ARAÚJO, Cláudia Helena dos Santos. Tecnologia e educação: algumas considerações sobre o discurso pedagógico contemporâneo. Campinas: Educação e Sociedade. 2012.

TAJRA, Sanmyra Feitosa. Informática na Educação: o uso de tecnologias digitais das metodologias ativas. 10.ed. São Paulo: Érica, 2019. 